\title{
Resources on tobacco prevention and control available to managed care organisations from the Centers for Disease Control and Prevention
}

\author{
Corinne G Husten
}

In the United States, national health objectives are described in "Healthy People 2000: national health promotion and disease prevention objectives". ${ }^{2}$ These objectives are currently being updated for the year 2010, and include the following objectives related to tobacco use cessation: (1) increase to $75 \%$ the proportion of cigarette smokers who stopped smoking for at least one day during the previous year; (2) increase to $95 \%$ the proportion of smokers who received advice to quit smoking from a health care provider during the previous year; and (3) increase to $100 \%$ the proportion of health plans that offer treatment for nicotine addiction (for example, counselling or pharmaceutical interventions). The support of managed care organisations is critical if the nation is to achieve these objectives.

This report describes some of the resources available to managed care organisations for preventing or reducing tobacco use. Most of the described resources are available from the Centers for Disease Control and Prevention (CDC), but other resources are also available. For example, several states (California, Massachusetts, Arizona, Oregon) have developed comprehensive tobacco control programs funded by tobacco excise taxes. State resources include clearinghouses, telephone counselling, information about model programs, and technical assistance. Other states may use tobacco settlement funds to develop similar resources.

At CDC, the Office on Smoking and Health $(\mathrm{OSH})$, which began as a clearinghouse, has compiled an extensive collection of literature and publications related to tobacco. A catalogue describes the materials available. Through an electronic database, users have access to 60000 abstracts from published articles on tobacco use. OSH also has a media campaign resource centre, which makes innovative print, radio, or television advertisements produced by the states available to health departments and other partners, thus saving development costs. Other resources which are available from $\mathrm{OSH}$ are guidelines and options papers containing information about treatment for tobacco use. For example, the recently published "Best practices for comprehensive tobacco control programs" ${ }^{3}$ contains a section on cessation.

Information resources at $\mathrm{OSH}$ can be accessed on the internet and by telephone, email, and a voice fax system.

Internet address: http://www.cdc.gov/ tobacco Information is arranged by topic (for example, cessation/quitting), which makes it easy to find and download relevant materials. It is also possible to access and search the electronic database and get information on the media campaign resource centre through the internet.

Telephone: (+1) 7704885705 By following the directions, you can either order materials (including media campaign materials) or you can speak to an information specialist. The media campaign resource centre also has its own telephone number: (+1) 3012317537 .

Email address: tobaccoinfo@cdc.gov Materials can be ordered or questions sent to the information specialists via email.

Voice fax system: (800)CDC-1311 (USA only). This is an electronic service whereby callers can order materials that are automatically sent to them by fax. When you call, the system prompts you about how to order. Materials such as fact sheets, quit tips, promotional materials, and many of the publications available on the internet can be ordered via voice fax.

Resources are also available to managed care organisations and health care systems from other areas of CDC. The Division of Adolescent and School Health ((+1) 770488 $3214)$ and $\mathrm{OSH}$ collaborate on issues related to preventing teenagers from using tobacco. The Division of Adult and Community Health ((+1) 770488 5484) has a group that works with managed care organisations on a variety of issues, including surveillance. There is also an Office of Health Care Partnerships at CDC ((+1) 770488 8186) that works closely with managed care organisations on a variety of issues, including those related to tobacco.

As noted above, health care systems and, in particular, managed care organisations are critical to reaching the Healthy People 2010 objectives for tobacco use cessation. CDC can be a valuable resource for these organisations.

1 US Department of Health and Human Services. Public Health Service. Healthy People 2000: national health promotion and disease prevention objectives. Washington DC: US Department of Health and Human Services, 1990. (DHHS Publication No (PHS) 91-50213)

2 US Department of Health and Human Services. Public Health Service. Healthy People 2000: midcourse review and Health Service. Healthy People 2000: midcourse review and
1995 revisions. Washington DC: US Department of Health and Human Services, 1995.

3 Centers for Disease Control and Prevention. Best practices for comprehensive tobacco control programs-August 1999. Atlanta, Georgia: US Department of Health and Human Services, Centers for Disease Control and Prevention, Office on Smoking and Health, August 1999. 